\title{
Design and Implementation of a Logistics Report Management System Based on Spring MVC
}

\author{
F. Zhang \\ Department of Automation \\ College of Mechatronics Engineering and Automation \\ Shanghai University \\ Shanghai Key Laboratory of Power Station Automation \\ Technology \\ Shanghai, China
}

\begin{abstract}
In order to meet the logistics industry report management flexibility, maintainability and other requirements, based on Microsoft SQL Server 2008 R2 database and Spring MVC framework of logistics report system design, combined with concrete practice process of the research and development of specific system architecture and the specific function of each module requirements, gives the detailed design and implementation process.
\end{abstract} MVC

Keywords- logistics report management system; report; spring

\section{INTRODUCTION}

In approving bills, aspects of the financial position, performance evaluation, data analysis and others is indispensable to a business enterprise, especially indispensable to logistic enterprise. It is the basic measures and means of enterprise management, basic business requirements, and the basis for implementing BI strategy. Each processing chain in traditional logistics statements have mutual split, there is no unified design, management, and maintenance. Each department of the enterprise periodical submits report to the relevant unit, and then presented to the higher level, and then the higher department will organize the report and submit to the supervisor. This greatly increases the labor costs, resulting in a waste of resources, information delays, the effectiveness and accuracy of information cannot be reported to the manager in a timely manner, leading to poor decisions, unpredictable consequences to the enterprise. Due to these shortcomings, this paper will state the operations of analysis, design and implementation of the Spring MVC framework based management system of logistics, logistics reporting system is constructed based on B / S mode network structure and routine business data queries, uploading and downloading, management and maintenance. System operation and maintenance is relatively simple, and can be access by different personnel from different locations, with different access privileges to access and manipulate data within the scope of business; business expansion is easy to share and very highly shared.[1].

\author{
S.J. Wang \\ Department of Automation \\ College of Mechatronics Engineering and Automation \\ Shanghai University \\ Shanghai Key Laboratory of Power Station Automation \\ Technology \\ Shanghai, China
}

\section{INTRODUCTION REPORT MANAGEMENT SYSTEM}

\section{A. Overall System Framework}

The system uses B / S network architecture model, through the navigation of the website users log in and browse to the operating system and send the request to the server; server responds to the user's request, will pop up the page to the user requested. This system is based on the Spring MVC framework design, from top to bottom, there are the presentation layers, [2], business logic and data persistence layer three-tier design. As shown in Figure 1.

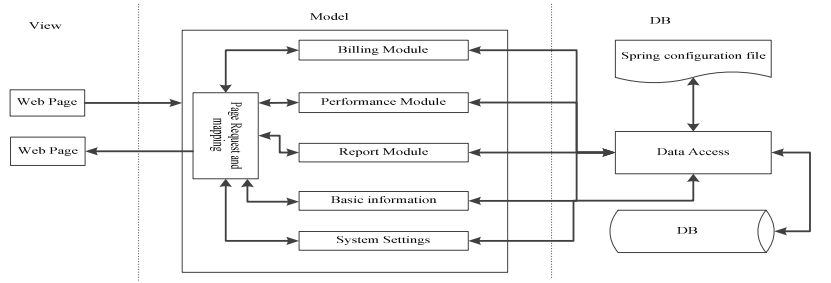

FIGURE I. FIGURE 1: FIGURE THREE-TIER SYSTEM AS A WHOLE

The presentation layer is mainly used to interact with the user and presents a variety of basic information, the system presents to the user the most direct page. Business logistic mainly used to achieve full functionality and business-related, role-based access control and workflow management, if it comes to access to the database, call the data access interface, the database will return information to the presentation layer. Data persistence layer mainly on the basis of information and data to achieve increased according to the needs of users, delete, change, and check; provide basic data for the upper level.

\section{B. Report Management System Design}

Report management system is mainly composed of five modules, including: billing, performance, reports, basic information, system settings. Billing module which is the most central part of the whole reporting system, all the basic information about the bill must be imported through the various parts of the billing module to the database; this module allows users to upload basic data, a detailed view of data record information. Uploaded data will automatically be imported and combined with business data generation supplier billing documents. Different levels of users can also modify, approvals, 
locking, imported bill file and, in addition, users can also view the history of the bill and the original bill file. By approving the bills only those bills and locked files, the financial officers can view and export data in order to verify the financial statements, are processed on financial operations; performance module is mainly used to upload the performance of the underlying data, and allows the user minimum permissions to view and modify some of the data; reporting module allows users to view various business reports, the reports can be very intuitive by reflecting the company's operating performance, performance appraisal, distribution of information, records and other information; basic information module for uploading inventory data, transaction data, add customers and suppliers, and set the account of other operations; Finally, system settings module is used to add or modify users, grant permissions, and roles operation. Module system function structure shown as in Figure 2.

\section{The main module workflow system}

1) Billing module. Billing module includes basic data, billing documents, bill approval documents, financial statements files, history, and original bill file.

\section{a) Basic Data}

In this module contain four parts, including: product, packaging, pricing, and additional costs. Users can upload, search, add, and modify data at this stage.

\section{b) Billing Documents}

The billing document contains three parts: billing information, shipping bills, bills invoiced. Users with authority can query, produce and export bulk billing data. However, when a user is modifying data, other users cannot change the data and the monitor will show that the data is under modification. In addition, the new modified data will still be under modification before it is being approved, and other users can only view and cannot modify. Only when this part of the data is approved, then can this part of the data can be modified by other users. Once the data is being approved and locked by the supervisor, then this data may not be modified by other users. (Note: Only the data being approved will be locked). After modification, approval, or a series of operations such as lock, then the user can export a single data table, or bulk export multiple data tables, otherwise, original data bill can be just obtained directly. Specific billing document approval workflow logic shown in Figure 3.

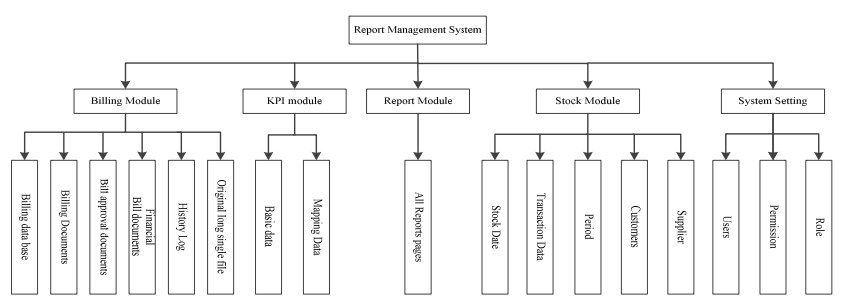

FIGURE II. SYSTEM FUNCTION BLOCK DIAGRAM OF THE STRUCTURE.

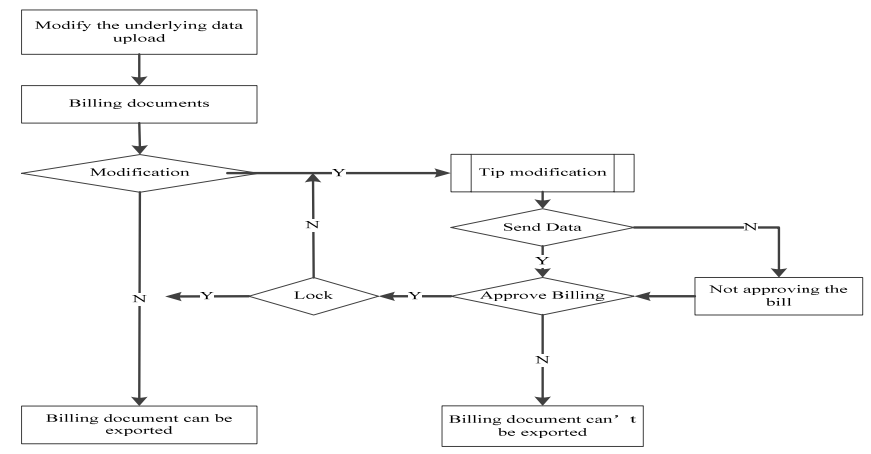

FIGURE III. BILLING DOCUMENT APPROVAL LOGIC FLOW.

c) Bill approval documents

Bill approving module contains three parts: billing information, shipping bills, and bills invoiced. Operated mainly by the approval of this part of the bill, the approver can view the data, approve the data, or reject the data.

\section{d) Financial statements document}

Financial billing module shows the locked billing data contains three parts: billing information, shipping bills, and bills invoiced. Mainly operated by finance personnel, financial staff can query and export the data to complete the business process financially, to verify the company's business data.

e) History

History module contains three main parts: billing information, shipping bills, and bills invoiced All users can view this part of the data, to understand modify records billing information.

\section{f) The original bill file}

Original billing document generation module which records without manually modifying the original data from the billing data.

2) Performance module. Performance modules include: basic data and matching data.

This part of the user upload corresponding data in these two modules which, after the upload is complete, and in the case of the data to ensure accuracy, the user can view the corresponding performance report page, specific business process shown in Fig.4.

3) Basic information module. The main basis of the information contains four parts, which are available from stock data, transaction data, account of customers and suppliers. The main purpose is to upload inventory information, transaction data, set account period, view and modify customer and supplier information.

\section{IMPLEMENTATION OF THE SYSTEM}

According to basic reporting system it needs analysis, which this system shows step by step functions of detailed implementation process that can be achieved in three steps.

Step One: Select the database

In addition, the system involves the development of report, in order to reduce the workload of developers, and the report 
can be presented effectively and design, selected Microsoft SQL Server 2008R2 as a platform for the database. Microsoft SQL Server 2008 R2 is a powerful and reliable data management system, which is rich and powerful, can effectively protect data, embedded applications, lightweight Web sites and applications, and the performance of local data storage area can be greatly improved. Such data not only can easily add, delete, change or search, but can also use Microsoft SQL Server 2008R2 comes BIDS (Business Intelligence Development Studio) to develop the report, can be said to serve two purposes, to achieve the development and design of the system reports seamless database compatible, so that not only solve the problem of data storage, but also solved the development of the report.[8,9].

\section{Step 2: Independent development report}

Since the development of the system reports and other business processes is not directly related, report design involves only the calls to the database data, therefore, system developer do not need to participate in the report of designing, report designers need the operation of the database, the establishment of good corresponding report, and then deploy it to the report server. Therefore, the design and development of reports and other modules of the system can be carried out concurrently. This will not only save a lot of development time and cost, but also allows system developers to focus on optimizing the design and performance of the system, without distracting the development of the report.

\section{Step 3: Connect the data source}

The system is developed based on the Spring MVC framework, Spring configuration file can configure a database connection, the connection to the database using XML configuration approach, which can greatly reduce the difficulty of developer, and can separated java hard-coded data from the database, at the same time take advantage of the convenience of Spring framework to management database, usually when proceeding Spring configuration we put it in a separate file in the configuration file jdbc.properties file, therefore when changing the database only needs to be changed the properties file's name and the corresponding port of the database, it is simple, portable and strong .

\section{A. System Development Environment}

(1) Development platform MyEclipse10.0.

MyEclipse10.0 is a very good and very powerful enterprise-level working platform, it is EclipseIDE further expansion and integration, not only in the software of database and JavaEE can we conduct a comprehensive design, deployment, but also application server integration greatly improved developers design speed. Myeclipse10 is JavaEE integrated development environment, is very powerful, whether it is coding, debugging, or testing, and publishing features are included in it .

\section{(2) Spring framework and IOC Inversion of Control}

Spring MVC is a further extension of the Spring framework. Web application design process, generally are developed using MVC architecture provides a pluggable architecture in Spring MVC, [5],so not only can directly select the Spring Web framework, it can also choose such as Hibernate and Struts2 frameworks. Since the Spring framework is configurable, it contains many other technical aspects on view, such as Velocity, JavaServer Pages (JSP) and POI technology. During the development process, Spring MVC framework developers do not have advance viewing of images nor does it have special requirements, therefore, it is impossible to use only JSP technology. This greatly increases the flexibility in terms of using the framework of view, for different developers it reduces the hardship of development, and because of the advantages of open sources Spring can be well accepted by the majority of developers.[6].

\section{B. Key Technologies}

(1) About the report is how to embed into the system.

When the report is completed independently developed, the need to develop a good report is embedded into the system for different personnel to view, to understand the current logistics system data details. Development of the report is based on development tools BIDS, when development is complete, simply deploy reports to the report server. Then is how the report will be introduced into the system, the system mainly goes through the use of annotations in the form of the Spring MVC framework will report request ID is returned to the JSP page, ID and JavaScript form by introducing the report to the JSP page. In use IFRAME tag returned by the server will report directly back to the HTML format of the report can be a JSP page,[4,7], the user can see the final presentation of the report. The advantage of this is the system developers only need to focus on the development of the system, so that developers do a special report statements. Directly eliminating the additional time and effort the developers spent on developing report system to accelerate the pace of progress in the system design. It is a distributed system development in the true sense. Each developer only needs to focus on their part of the development.

(2) The system settings, permissions, roles management.

Admin user has all the privileges of the system. Can arbitrary the system's operation. Including adding users, permissions granted, giving roles. The bill operator can operate the entire billing module, including billing data query information, export, production, submission, locking, logging operations such as query statements. Financial officers only have the rights to see the bill. Bill approver logs and billing inquiries have approval bill rights. Basis of the information department of the company has permission to upload basic business data.[3]. Performance department user has permission to generate the report. Specific system permissions distribution shown in Figure.5. 


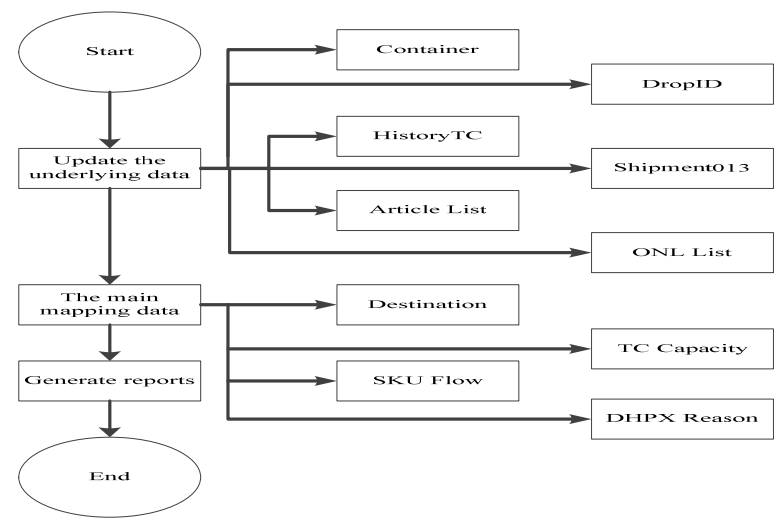

FIGURE IV.PERFORMANCE BUSINESS FLOWCHART OF FIG.

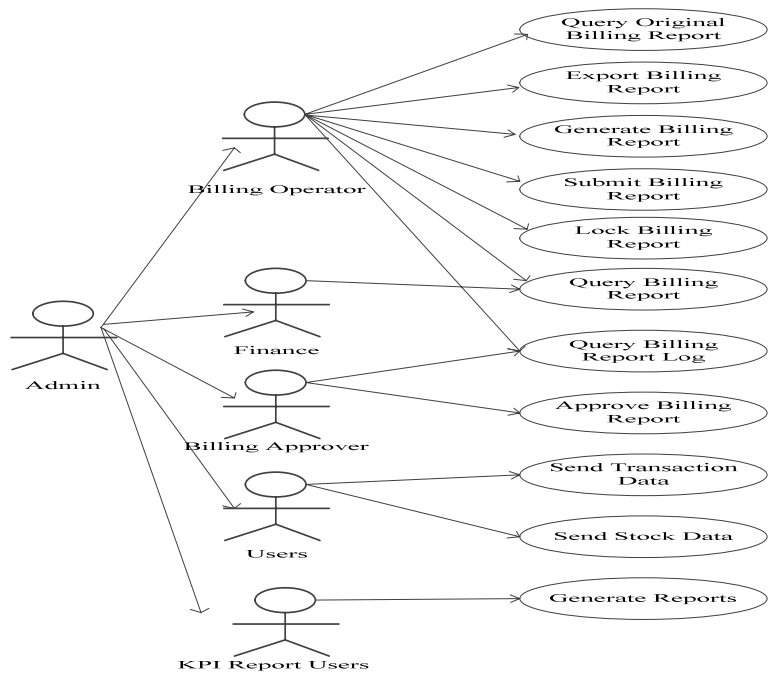

FIGURE V. DISTRIBUTION SYSTEM PRIVILEGES.

\section{SYSTEM APPLICATION RESULTS}

This research report logistics management system is a comprehensive display and maintains the logistics business, at present, has been used in specialized logistics companies in the construction and management, and promotes information sharing aspects of the company plays an active role. The operation of the system through visualization, management prevention mechanism to achieve a flexible management and presents the company's internal data. Effective solution to series of data delay, human error message appears, greatly improving the company's performance evaluation, financial management, report rendering efficiency. Company information maximized and effective sharing of the information of the company profits maximized efficient use and share. However, with the company's business needs, the systems will contains imperfection, which we also need to constantly improve and perfect.

\section{ACKNOWLEDGMENTS}

The manuscript is supported by the Key industrialization projects (No. 12YZ010).

\section{REFERENCES}

[1] Liu Jing, criminal possession of a dais, Gong Fan Lei. SSH -based university MBA Management System Design and Implementation J. Computer Applications and Software, 2011, 28 (11): 261 - 263, 282.

[2] Zhang Fei, Wang Jing, Yang Pengrui, Yan Li. Computer Account Management System Design and Implementation J. Computer Applications and Software, 2011, 28 (6): 218 - 219, 246.

[3] Liu Tingting Jiang Yuming Fu Jingtao integrated J2EE framework to build e-commerce systems reusable J, Journal of Computer Applications, 2006, 26( 11 ) : 2769-2772

[4] Dong Haiyan, Wang Weidong. Based on JSF, Spring and Hibernate technical information integrated management system J. Computer Applications and Software, 2012,29 ( 5 ) : 212 - 214, 218.

[5] Gary Mak forward, Ding Xuefeng translated. SPRING Raiders M. Beijing: People's Posts and Telecommunications Press, (2009).

[6] Hsu Wen Jia, ZHAO Ying-kai. Spring MVC and Hibernate for applications WEB Development J. Computer Applications and Software, 2008, 25 (2): 264 - 265, 283.

[7] Wang Yingying, Qiao Xiaoyan, Lvting Hua, et al. JSP Web Development Case tutorial M. Beijing: Tsinghua University Press, (2013).

[8] (The United States) Larsen book, Xue Ying, Dong Liang.Translation. Microsoft SQL Server 2005 Reporting Services expertstutorial M. Beijing: Tsinghua University Press, (2010).

[9] Xie Bangchang. SQL Server 2008 R2: data mining and business intelligence -based combat and advanced case M. Beijing: China Water Power Press, (2011) 